\title{
Student Judgments of the Importance of Image- and Ethos-Related Professionalism Attributes/Behaviors to the Work Environment and Their Shift over Time
}

\author{
Jennifer Bechkoff \\ San Jose State University
}

\begin{abstract}
An exploratory study was conducted to determine which attributes/traits marketing students feel are most important for them to learn for workplace professionalism. And in order to determine perceived shifts in professionalism importance levels over time, students' perceptions of their parents '/guardians' judgments were ascertained to see whether there is a significant difference between them. It is hypothesized that societal norms for professionalism are shifting away from image-related ones and more toward those that are ethos-related. Gender, years of work experience, generation, and time spent living in the USA were investigated as potential moderators. Both qualitative and quantitative preliminary data were collected.
\end{abstract}

\section{INTRODUCTION}

Professionalism is the type of behaviors or attributes one would expect from a professional person. Examples of professionalism include such things as dressing appropriately, demonstrating a strong work ethic, impression management, speaking/writing in a manner appropriate to the audience, and being punctual. Baby Boomers \& Gen Xers have been in the workforce the longest, with Millenials and those from the iGeneration being the bulk of new hires.

With Millennials and the iGeneration entering the workforce, who grew up with a larger technologyto-human interaction ratio than did Baby Boomers and Gen Xers, employers have been noting a lack of professionalism with potential new hires (Meola, 2016; Anthony \& Garner, 2016; Clarke, 2016; Tulgan, 2016). Less social interaction means less of a chance to hone professionalism skills. As such, business colleges around the country have started adding Soft Skills courses to their undergraduate curriculum.

It is the duty of professors to help students hone these skills. Higher education can and should be developing students' personality characteristics into employability skills (Villar \& Albertin, 2010). The need for professionalism among students in higher education is a topic of much discussion among faculty, and current research shows business colleges can be successful in increasing student growth in the area of business professionalism (Wresch \& Pondell, 2015). But what professionalism skills should faculty teach?

The perceived requirements for having professionalism differ among people. For example, wearing jeans may be acceptable attire to a business meeting for some, while others insist on suits. There are many variables that alter professionalism norms such as industry type (e.g., farming vs. finance), job position (e.g., counter help vs. management), and location (e.g., Silicon Valley vs. New York City). On a micro 
level, one's culture, age, and work experience also affect his or her perceptions of what is important for demonstrating professionalism in the workplace.

If you take a bird's eye view of various behaviors and attributes that represent professionalism, they can be classified into two types: Ethos and image. Ethos (the Greek word for character) is internal; it is one's moral qualities, guiding beliefs, and ethical appeal. Examples of ethos in the context of professionalism include integrity, honesty, conscientiousness, and responsibility. Converse to ethos, image is an external demonstration; it is how a person is represented in their external form, structured by visual information. Professionalism examples of image-related attributes/behaviors include appropriate attire, dining etiquette, body language, and proper handshake.

According to Tymon (2013), student views of which skills are important is crucial because they are the intended recipient of their development. As such, the purpose of this research is to investigate student judgments of professionalism skill importance to help modernize professionalism curriculum. How do marketing students feel specific attributes and behaviors are for professionalism in the workplace? An exploratory study was conducted. Both qualitative and quantitative preliminary data was collected.

\section{HYPOTHESES}

With the increase in technology usage comes a decrease in human interaction. Not only did Millennals and the iGeneration grow up with more technology, many of the jobs available for them are for remote work as satellite employees working from home. There is an increase in isolationism that wasn't prevalent before. This may be changing the face of professionalism as we view it today. Is there a generational difference in what is considered professional? It is hypothesized that,

$\boldsymbol{H}_{1}$ : There is a significant difference between the professionalism attributes and behaviors students judge as important versus what they perceive their parents (or guardians who raised them) judge as important.

Personal expression via hair color, styles, facial hair, and body are more commonplace than before. As work and interpersonal communication is done more with technology than in person, perhaps less importance is placed on physical appearance for work. Social movements such as \#MeToo and \#BlackLivesMatter are calling for job removal from employees who partake in unethical/immoral behavior. Hence, it is hypothesized that,

$\boldsymbol{H}_{2}$ : Societal norms for professionalism attributes and behaviors are shifting away from image-related ones and more toward those that are ethos-related.

\section{METHOD}

\section{Participants and Design}

Eighty-four undergraduate marketing students (36 male and 48 female) from a large California university were asked to participate in a survey on professionalism for extra credit. A list of fifty-one professionalism behaviors and attributes were created from a brainstorming activity with several business professors and business professionals in an attempt to produce an exhaustive list. Participants were asked to rate on a scale from 1(extremely unimportant) to 7(extremely important) how important they felt those attributes/behaviors were to professionalism in the workplace. They were also asked to rate how important they thought those particular professionalism attributes/behaviors were in the eyes of the parent/guardian who raised them. Several open-ended questions were asked to understand what professionalism means to the participants, how important it is, whether it should be taught in college, and what they felt the main differences were between their own viewpoints and their perception of their parents' viewpoints. Gender, years of work experience, generation, and time spent living in the USA were also investigated as potential moderators. 


\section{RESULTS}

A paired t-test was conducted to compare mean differences between the levels of importance of fiftyone professionalism behaviors/attributes based on their own views and the views they believe their parents have. Results showed a significant difference between thirty-one pairs (significance levels and means displayed in Table 1 below) and a nonsignificant difference between twenty pairs (means displayed in Table 2 as it is interesting to see which attributes/behaviors students feel are the same as their parents' views.)

TABLE 1

JUDGMENTS OF IMPORTANCE FOR PROFESSIONALISM IN THE WORK ENVIRONMENT - SIGNIFICANT PAIRS

\begin{tabular}{|c|c|c|c|c|}
\hline \multirow{2}{*}{$\begin{array}{c}\text { Ethos/I } \\
\text { mage }\end{array}$} & \multirow[b]{2}{*}{ Professionalism Attribute/Behavior } & \multirow[b]{2}{*}{ Sig. } & \multicolumn{2}{|c|}{ Means } \\
\hline & & & You & $\begin{array}{c}\text { Parent/ } \\
\text { Guardian }\end{array}$ \\
\hline $\mathrm{E}$ & Flexibility & 0.009 & 5.89 & 5.41 \\
\hline $\mathrm{E}$ & Stress management & 0.000 & 6.28 & 5.37 \\
\hline $\mathrm{E}$ & Helpfulness & 0.001 & 6.07 & 5.66 \\
\hline $\mathrm{E}$ & Work ethic & 0.052 & 6.58 & 6.39 \\
\hline $\mathrm{E}$ & Conflict resolution & 0.000 & 6.32 & 5.72 \\
\hline $\mathrm{E}$ & Giving \& Receiving criticism & 0.007 & 6.06 & 5.58 \\
\hline & Awareness of personal responsibility as a listener or & & & \\
\hline $\mathrm{E}$ & audience member & 0.000 & 6.03 & 5.49 \\
\hline $\mathrm{E}$ & Humility & 0.045 & 5.94 & 5.65 \\
\hline & Symbols you display in your office/workstation & & & \\
\hline I & (pictures, figurines, pop culture references, etc.) & 0.014 & 4.87 & 4.27 \\
\hline 1 & Use of preferred pronouns & 0.000 & 5.55 & 4.83 \\
\hline 1 & Email professionalism & 0.000 & 6.46 & 5.49 \\
\hline 1 & Video conferencing etiquette & 0.000 & 5.85 & 4.86 \\
\hline 1 & Social media professionalism & 0.000 & 5.96 & 4.76 \\
\hline 1 & Proper grammar, mechanics, punctuation in speech & 0.003 & 6.14 & 5.68 \\
\hline 1 & Proper capitalization in writing & 0.001 & 6.32 & 5.72 \\
\hline 1 & Business travel etiquette & 0.001 & 5.77 & 5.13 \\
\hline 1 & Appropriate Hair (Head \& facial)* & 0.007 & 5.48 & 6.10 \\
\hline 1 & Hygiene & 0.003 & 6.65 & 6.35 \\
\hline 1 & Physical Fitness & 0.020 & 5.01 & 4.46 \\
\hline 1 & Tattoos, body piercings, body art* & 0.022 & 4.03 & 4.63 \\
\hline I & Handshake & 0.002 & 6.07 & 5.42 \\
\hline 1 & Body language & 0.004 & 6.06 & 5.51 \\
\hline 1 & Eye contact & 0.007 & 6.32 & 5.79 \\
\hline 1 & Politically correct speech & 0.017 & 5.45 & 5.01 \\
\hline 1 & Making proper introductions & 0.040 & 6.11 & 5.73 \\
\hline 1 & Impression management/Personal brand & 0.000 & 5.89 & 5.06 \\
\hline 1 & Speaking in a manner appropriate to the audience & 0.002 & 6.38 & 5.87 \\
\hline 1 & Writing in a manner appropriate to the audience & 0.000 & 6.38 & 5.73 \\
\hline
\end{tabular}

Note: Higher means indicate greater importance for professionalism in the workplace.

*Students perceive their parents find the attributes to be more important in the workplace than they do. 
TABLE 2

JUDGMENTS OF IMPORTANCE FOR PROFESSIONALISM IN THE WORK ENVIRONMENT - NONSIGNIFICANT PAIRS

\begin{tabular}{|c|c|c|c|c|}
\hline \multirow{2}{*}{$\begin{array}{l}\text { Ethos/ } \\
\text { Image }\end{array}$} & \multirow[b]{2}{*}{ Professionalism Attribute/Behavior } & \multirow[b]{2}{*}{ Sig. } & \multicolumn{2}{|c|}{ Means } \\
\hline & & & You & $\begin{array}{l}\text { Parent/ } \\
\text { Guardian }\end{array}$ \\
\hline $\mathrm{E}$ & Integrity & n.s. & 6.37 & 6.44 \\
\hline$E$ & Respectfulness & n.s. & 6.51 & 6.52 \\
\hline$E$ & Responsibility & n.s. & 6.54 & 6.55 \\
\hline$E$ & Honesty & n.s. & 6.51 & 6.34 \\
\hline$E$ & Persuasion & n.s. & 5.46 & 5.20 \\
\hline$E$ & Organization & n.s. & 6.08 & 5.96 \\
\hline$E$ & Punctuality & n.s. & 6.37 & 6.13 \\
\hline $\mathrm{E}$ & Professional (respectful, clear, effective) tone & n.s. & 6.41 & 6.38 \\
\hline $\mathrm{E}$ & Respecting others' professional positions/authority & n.s. & 6.35 & 6.20 \\
\hline $\mathrm{E}$ & Humor & n.s. & 5.46 & 5.42 \\
\hline $\mathrm{E}$ & Time management (not procrastinating) & n.s. & 6.20 & 6.25 \\
\hline $\mathrm{E}$ & Confidence & n.s. & 6.21 & 5.97 \\
\hline 1 & $\begin{array}{l}\text { Proper grammar, mechanics, punctuation in } \\
\text { writing }\end{array}$ & n.s. & 6.31 & 6.01 \\
\hline 1 & Maintaining composure when challenged & n.s. & 6.23 & 6.07 \\
\hline 1 & Appropriate attire (Clothes, shoes, accessories) & n.s. & 6.06 & 6.10 \\
\hline 1 & Cleanliness & n.s. & 6.32 & 6.34 \\
\hline 1 & Not getting too personal at work & n.s. & 4.93 & 5.14 \\
\hline 1 & Gift giving & n.s. & 4.21 & 4.32 \\
\hline 1 & Business dining etiquette & n.s. & 5.48 & 5.27 \\
\hline 1 & Thank you notes & n.s. & 4.80 & 5.04 \\
\hline 1 & Cell phone etiquette & n.s. & 5.73 & 5.32 \\
\hline 1 & Smile & n.s. & 5.89 & 5.63 \\
\hline 1 & Posture & n.s. & 5.66 & 5.56 \\
\hline
\end{tabular}

Note: Higher means indicate greater importance for professionalism in the workplace.

$\mathrm{H}_{1}$ was partially supported. Further, student participants believe all significantly different traits to be more important than they think their parents/guardians regard them, except for two: Tattoos/body piercings/body art and appropriate hair (head \& facial). In the latter two cases, students perceive their parents to find those attributes more important in the workplace; this is likely due to societal norm fluctuation with regard to acceptable displays of personal expression. Chart 1 of the appendix illustrates the importance level of each attribute/behavior used in the study as judged by the student participants. No significant differences were found between professionalism attributes/behaviors and gender, culture (e.g., time spent living in the USA), generation born (all respondents were either Millennials or iGeneration), or years of work experience. It is important to note that less than $6 \%$ of students had no work experience and over half of them had more than five years of work experience. Hence, the participants in this study have a functional understanding of workplace professionalism. See Figure 1 below for a breakdown of participants' work experience. 


\section{FIGURE 1}

\section{PARTICIPANTS' YEARS OF WORK EXPERIENCE}

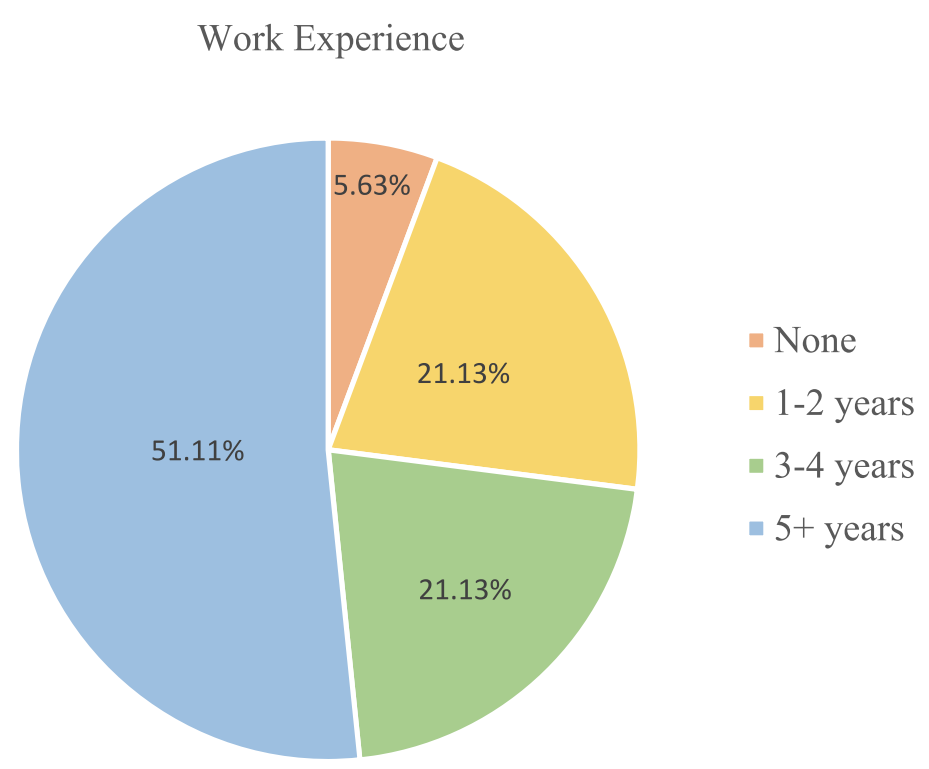

It is noteworthy that students indicated all fifty-one listed professionalism attributes and behaviors as important for workplace professionalism and felt all items should be taught in college. As this may or may not be feasible, a list of what items students found to be most important (rated moderately important to extremely important) is listed in Figure 2 below. 


\section{FIGURE 2 \\ STUDENT JUDGMENTS OF IMPORTANCE FOR PROFESSIONALISM IN THE WORK ENVIRONMENT}

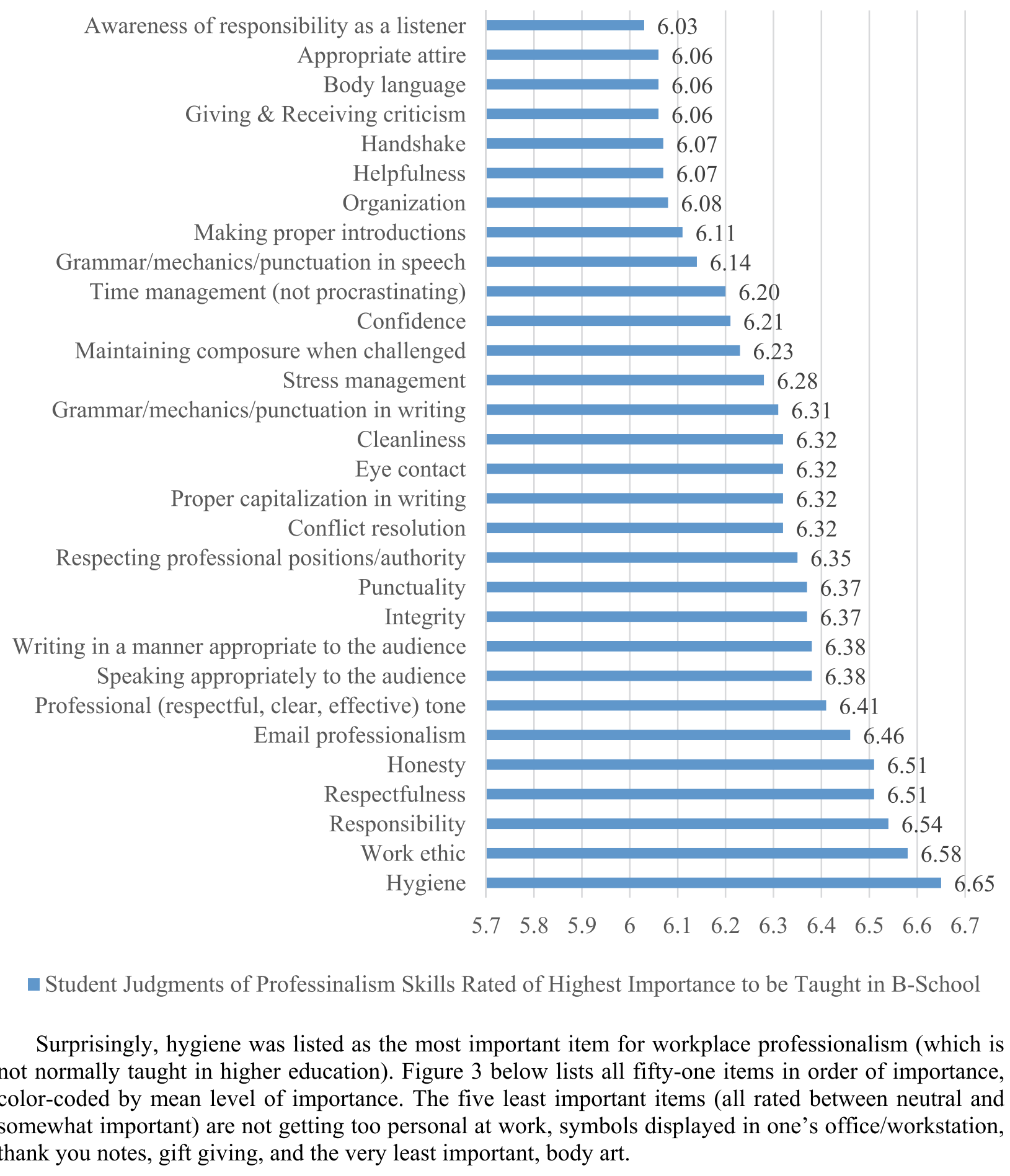




\section{FIGURE 3 \\ PROFESSIONALISM ATTRIBUTES AND BEHAVIORS BY ORDER OF STUDENT PERCEIVED IMPORTANCE}

1. Hygiene (6.65)

2. Work ethic (6.58)

3. Responsibility (6.54)

4. Respectfulness (6.51)

5. Honesty (6.51)

6. Email professionalism (6.46)

7. Professional (respectful, clear, effective) tone (6.41)

8. Speaking in a manner appropriate to the audience (6.38)

9. Writing in a manner appropriate to the audience (6.38)

10. Integrity (6.37)

11. Punctuality (6.37)

12. Respecting others' professional positions/authority (6.35)

13. Conflict resolution (6.32)

14. Proper capitalization in writing (6.32)

15. Eye contact (6.32)

16. Cleanliness (6.32)

17. Proper grammar, mechanics, punctuation in writing (6.31)

18. Stress management (6.28)
19. Maintaining composure when challenged (6.23)

20. Confidence (6.21)

21. Time management (not procrastinating) (6.20)

22. Proper grammar, mechanics, punctuation in speech (6.14)

23. Making proper introductions (6.11)

24. Organization (6.08)

25. Helpfulness (6.07)

26. Handshake (6.07)

27. Giving \& Receiving Criticism (6.06)

28. Body language (6.06)

29. Appropriate attire (Clothes, shoes, accessories) (6.06)

30. Awareness of personal responsibility as a listener or audience member (6.03)

31. Social media professionalism (5.96)

32. Humility (5.94)

33. Flexibility (5.89)

34. Impression management/Personal brand (5.89)

35. Smile (5.89)
36. Video conferencing etiquette (5.85)

37. Business travel etiquette (5.77)

38. Cell phone etiquette (5.73)

39. Posture (5.66)

40. Use of preferred pronouns (5.55)

41. Appropriate Hair (Head \& facial)

42. Business dining etiquette (5.48)

43. Humor (5.46)

44. Persuasion (5.46)

45. Politically correct speech (5.45)

46. Physical Fitness (5.01)

47. Not getting too personal at work (4.93)

48. Symbols you display in your office/workstation (pictures, figurines, pop culture references, etc.) (4.87)

49. Thank you notes $(4.80)$

50. Gift giving (4.21)

51. Tattoos, body piercings, body art (4.03)

\section{Note: Items are color-coded by mean level of importance; means are in parentheses}

Researcher judgment sorted the behaviors/attributes into ethos and image categories. There were 20 ethos-related and 31 image-related behavior/attributes in the study. Of the top 10 important attributes/behaviors judged by students, 6 were ethos and 4 were image; surprisingly, of the top 10 by student perceptions of their parents' judgments, 8 were ethos and 2 were image. Similarly, of the bottom 10 (least important) attributes behaviors, 2 were ethos-related as judged by the students, while none were ethos-related as judged by students' perception of their parents' judgements. $\mathrm{H}_{2}$ was not supported. Contrary to researcher hypothesis, data indicate students perceive ethos-related professionalism attributes/behaviors to have become slightly less important over time than image-related ones.

\section{Qualitative results}

Students generally find themselves to judge professionalism as more important than they believe their parents do. A respondent quotes confirms the quantitative findings.

- "My parents are more relaxed when it comes to professionalism and I am very strict with myself and very respectful to people..." 
- "My parents don't really care much for professionalism now. Back then, they used to be teachers so they cared about being professional. I care more about being professional since I'm about to enter the workforce."

- "The main differences are that I treat professionalism more serious in terms of proper grammar, gestures, and etiquette, while my parents are more laid back and do not care if they don't show too much professionalism towards others."

Advancement in technology has had an effect on professionalism focus over the years. Millennials and those from the iGeneration are sensitive to professionalism in environments with non-human contact.

- "The main differences from me and my parents can be found on the questions relating to behavior and etiquette on technology. A bit of context, my mom just started using her own personal smartphone this year. With that said there is a huge disconnect of the professional etiquette that is needed to transfer over with modern technology. I'm confident that once she is comfortable with using a smartphone she will begin to incorporate her own professionalism into how she uses her device."

- "The main differences between my parent's views on professionalism and my own come along with the recent increase in technological communications and social media platforms since my parents began working in the late 70 's. Our generation prioritizes online marketing tactics and a professional brand image on social media platforms in the current work environment."

- "My parents place less value on the impact of social media. I think social media can either help you or hurt you in a work environment."

Although students find professionalism more important than their parents do, they believe their parents are more heavily focused on image-related professionalism, despite the quantitative results revealing the contrary, except with regard to hair and body art.

- "...I noticed that it is becoming more relaxed in the workplace nowadays. For instance, many of the companies now have a dress code that is more easygoing. While many older companies still have the suit and tie policy, many companies like Google and Apple have adopted a dress code that allows employees to be comfortable in their own clothes. I noticed that the term professionalism still vitally exists, but it is defined differently for me and my parents. For my parents, it is about how people dress (suit and tie) and how you act towards others. For me, it is about being responsible and ethical in the work that I do that will reflect how my colleagues in the workplace will see me."

- "Some differences of professionalism include the perception of tattoos and being polite. My parents say 'you're welcome' whereas I might say 'no problem'."

- "Tattoos and other aspects of physical appearance has become normalized for me, where as it still is newer in the work force for my parents."

- "My parents' view on professionalism is more traditional and old school while mines [sic] are more modern. I think tattoos, piercings, dyed hair (red, blue, etc.) is [sic] perfectly fine in a workplace because it does not affect my work or anyone else's. My parents think the total opposite, 'You cannot get a corporate job with tattoos!"

\section{DISCUSSION}

The present study is exploratory in nature, adding data to discussions of which professionalism traits are perceived to be most important. Although this is from a student, not an employer perspective, the results found are still valuable. Current employers mostly consist of Baby Boomers and Gen Xers. What professionalism attributes they feel are important in the work place will be less significant as Millennials and iGen workers move up in the workforce and become the key decision-makers themselves. They will be the ones who develop the next societal shift in professional norms. 
When asked, every participant believed professionalism should be taught in college. According to Jackson (2013), "students placing a high value on what they are learning may also impact on their ability to transfer acquired skills across different contexts, such as from the university classroom to the workplace." The list of what they perceive to be most important for professionalism in the work environment can be useful when designing the marketing education curriculum as student input is important for updates and changes for improvement (MacCallum \& Casey, 2017). Class exercises and lectures can be peppered via micro-insertions with content that helps students grow in these specific areas.

\section{LIMITATIONS \& FUTURE RESEARCH}

The results from this study are from participants living in Silicon Valley; data may change depending on location and are thus not generalizable. Student perceptions of their parents' judgments may differ significantly from parents' actual judgements. It is planned for future research to survey the parents/guardians themselves. The professionalism categories were researcher sorted into ethos and image. Future research should perform a factor analysis or manipulation check for confirmation of which behaviors/attributes are image-related and which are ethos-related, and to perhaps determine other latent categories.

\section{REFERENCES}

Anthony, S., \& Garner, B. (2016). Teaching soft skills to business students: An analysis of multiple pedagogical methods. Business and Professional Communication Quarterly, 79(3), 360-370. doi: $10.1177 / 2329490616642247$

Clarke, M. (2016) Addressing the soft skills crisis. Strategic HR Review, 15(3), 137-139.Jackson, D. (2013). Student perceptions of the importance of employability skill provision in business undergraduate programs. Journal of Education for Business, 88, 271-279.

MacCallum, J., \& Casey, S.C. (2017). Enhancing skills development and reflective practise in students during their programme of study. New Directions in the Teaching of Physical Sciences, 12(1). Retrieved from https://www.napier.ac.uk/ /media/worktribe/output-1010382/enhancingskills-development-and-reflective-practise-in-students-during-their-programme-of.pdf

Meola, C. C. (2016). Addressing the needs of the Millennial workforce through equine assisted learning. The Journal of Management Development, 35(3), 294-303.

Tulgan, B. (2016). Bridging the soft skills gap. Chief Learning Officer, 15(4), 66.

Tymon, A. (2013). The student perspective on employability. Studies in Higher Education, 38(6), 841856.

Villar, E., \& Albertin, P. (2010). 'It is who knows you'. The positions of university students regarding intentional investment in social capital. Studies in Higher Education, 35(2), 137-154. DOI: $10.1080 / 03075070902957080$

Wresch, W., \& Pondell, J. (2015). Assessing cocurricular impacts on the development of business student professionalism: Supporting rites of passage. Journal of Education for Business, 90, 113-118. 